\title{
Medios, imagen corporal y género
}

\section{Elsie McPhail Fangerlang ${ }^{\dagger}$}

Este artículo se inserta en el marco de los estudios sobre la cultura urbana y analiza la imagen corporal de hombres y mujeres en diversos espacios, con ayuda de herramientas etnográficas.

Busca, en primer lugar, descubrir y describir estructuras desde las cuales se producen, perciben e interpretan los símbolos de la cultura inscritos en el cuerpo a través del espejo de los medios impresos y electrónicos, así como espacios publicitarios y mercadotécnicos.

Por otro lado, explora territorios citadinos en donde se rinde culto a la imagen corporal, lugares frecuentemente marginados por los estudios sociales por considerarlos banales, superficiales, territorios en donde aparentemente se cultiva el cuerpo y no el espíritu.

Ejemplos de lo anterior son peluquerías, estéticas femeninas y unisex, clubes deportivos, gimnasios, parques recreativos, clínicas de belleza y nutrición, centros comerciales, clínicas de cirugía plástica, boutiques, por nombrar sólo algunos de estos espacios.

No es que el culto por el cuerpo y la imagen que proyectan sean privativos de estos espacios, sino que son lugares en donde esta situación se encuentra exacerbada. Es ahí en donde se localizan de manera más explícita las definiciones de belleza "universal" vinculadas con imágenes de éxito y perfección.

Como diría Lipovetsky (1987: 49), son lugares en donde se refuerza el individualismo, marcado por el culto de la autonomía individual del cuerpo, representantes por excelencia de la era del vacío, que conlleva nuevas actitudes de apatía, indiferencia, narcisismo, en donde la consigna es mirarse el ombligo.

Watson (2001: 23a) afirma que la nueva obsesión por uno mismo es considerada por la sociedad moderna condición necesaria para elevar la autoestima. Señala que ahora la gente aburrida tiene permiso para aburrir a

1. Departamento de Educación y Comunicación. Universidad Autónoma MetropolitanaXochimilco. Correo electrónico: mcphail@cueyatl. uam. mx. 
los demás con el más aburrido de los temas: ellos: "porque yo lo valgo, mis necesidades, mis asuntos, mi vida" y el peor de los daños que ha causado la nueva sociedad de yoyos es en el arte de conversar.

El individualismo es el nuevo estado histórico propio de las sociedades democráticas avanzadas que trasplantan los medios hacia geografías de desarrollo medio y bajo como México.

El trabajo que se presenta sugiere enfrentar las materialidades de la vida cotidiana para comprender la cultura a partir de la imagen corporal. A través del análisis de imágenes, textos y lo que dicen los sujetos acerca de su imagen corporal se pretende analizar construcciones de hombre y mujer estratificadas por edades, etnias, clases sociales, tallas, en donde ciertas prácticas son manifestaciones de poder de un grupo sobre otro, marcando territorios de exclusividad y exclusión.

También se busca señalar las contradicciones en discursos publicitarios tomados habilidosamente de las consignas del movimiento feminista sobre autonomía de género y su contraparte materializada en imágenes disciplinarias y reduccionistas del cuerpo.

\section{Feministas y medios}

El trabajo teórico y práctico de las feministas ayudó a reconocer nuevos cautiverios en los cuales caía la mujer una vez que parecía haberse liberado de los antiguos a partir de los movimientos de liberación femenina del decenio de 1960. En su libro intitulado El mito de la belleza, escrito en 1991, Wolf explicaba la dualidad: las mujeres empezaban a disfrutar libertades que antes no estaban a su alcance y sin embargo las encuestas informaban que no se sentían satisfechas. Esto se debía a asuntos aparentemente frívolos, cosas que no debían importar, pero que sí importaban. Muchas se avergonzaban de admitir que asuntos aparentemente tan triviales como la apariencia física, los cuerpos, los rostros, el pelo, la ropa, sí importaban.

Parecía que entre más obstáculos legales y materiales rebasaba la mujer, se le presentaban imágenes más estrictas de belleza femenina. Por un lado, las mujeres rebasaron la estructura de poder en el decenio de 1980 y simultáneamente crecían los trastornos alimentarios considerablemente y la cirugía cosmética se convertía en la especialidad médica con mayores tasas de crecimiento.

Las mujeres encuestadas reportaban que preferían perder peso que lograr una meta profesional. La autora cita investigaciones recientes que muestran que al interior de la mayoría de las mujeres profesionistas atractivas y exitosas se encuentra un inframundo constituido por definiciones de belleza, baja 
autoestima, obsesiones por la apariencia, culto por la imagen corporal y terror frente al envejecimiento estimulado por los medios.

Según Wolf, se trata de una ofensiva en contra de la liberación femenina que utiliza imágenes de belleza femenina como arma política en contra del avance de las mujeres.

Al liberarse de la mística femenina de la domesticidad, la maternidad, la castidad, la pasividad y la abnegación, el mito de la belleza tomó su lugar y se expandió para ejercer control sobre ellas.

El feminismo proporcionó leyes en contra de la discriminación basada en el género, y de inmediato evolucionaron las leyes en EE.UU. y Gran Bretaña que discriminaban por la apariencia.

Ya desde el decenio de 1960 Friedan denunciaba la promoción de místicas femeninas a través de la publicidad que promovía la "felicidad" del ama de casa en la comercialización de productos caseros, y paralelamente las industrias dietéticas y del cuidado de la piel se transformaron en censores de la nueva mujer que aparecía ahora en anuncios de mujeres jóvenes y emprendedoras como modelo de la nueva femineidad (Friedan, 1963: 28).

La revolución sexual promovió el descubrimiento de la sexualidad femenina y la pornografía invadió el mercado para minar a la mujer en su floreciente autoestima.

Los derechos reproductivos dieron a las mujeres occidentales el control sobre sus cuerpos y el peso de las modelos para la industria de la moda cayó hasta llegar a $23 \%$ por debajo de la mujer promedio estadounidense, causando el aumento exponencial de los trastornos alimentarios clasificados en foros recientes como epidemia. En ese marco se promovieron alimentos sanos, dietas y tallas corporales para despojar a la mujer del control sobre su cuerpo.

Las mujeres politizaron el ámbito de la salud y paralelamente aparecieron tecnologías invasivas y cirugías cosméticas para adecuar los cuerpos femeninos a las necesidades de la publicidad (Wolf, 1991: 12).

Afirma Wolf que la ofensiva es tan violenta porque la ideología de la belleza es el último reducto de las viejas ideologías femeninas.

Por su parte, el texto de Bordo, cuyo título Carga (peso) insoportable: feminismo, cultura occidental y cuerpo, compilación de sus escritos y conferencias publicados en 1993, ofrece una interpretación del cuerpo femenino como construcción cultural en el mundo occidental, cuyo énfasis radica en la repercusión en trastornos alimentarios, reproducción y concepciones del yo. Sus textos pretenden demostrar cómo el destalle más trivial en apariencia revela valores culturales y patologías.

Se pronuncia en contra de quienes proponen la heterogeneidad de la cultura y afirma que existen contradicciones culturales occidentales dominantes y normalizadoras del género, y extrae ejemplos de la publicidad. Afirma que es necesario reconocer su especificidad y el terreno que dominan para 
contrarrestarlas; analiza a través de la historia las modificaciones que ha experimentado el cuerpo femenino y demuestra cómo esas alteraciones producen una constante guerra de la mujer con su cuerpo. Explora la fascinación humana con el hambre, el deseo, el control y los efectos que tiene en la vida de las mujeres.

También ella registra mensajes esquizofrénicos en los discursos publicitarios: autonomía e individualismo frente a imágenes de cuerpos sujetos a una estricta vigilancia. Afirma además que los altos índices de trastornos alimentarios son la conclusión lógica de una estructura contradictoria de femineidad en sociedades occidentales capitalistas, que enfatizan el poder de las imágenes mediáticas en la disciplina y alineación del cuerpo femenino, haciendo de él un territorio de opresión (1993: 322).

Nasser (1997: 13), por su parte, ha extendido ese modelo a otras latitudes, atribuyendo el surgimiento de problemas de inseguridad, autoestima y trastornos alimentarios en países no occidentales a la globalización cultural, en especial a raíz del arribo de los medios.

Afirma que el trasplante de íconos universales mediáticos ha sido definitorio en la implantación de nuevos patrones de belleza en Egipto, su país de origen, y que es necesario hacer estudios transculturales para establecer comparaciones con culturas similares.

El estudio de Becker analiza la incidencia directa de los medios en percepciones sobre el cuerpo en países de desarrollo medio y bajo. En las islas Fiji estudió los patrones de belleza de mujeres antes y después de la introducción de la televisión a la isla. A lo largo de tres años registró severas modificaciones en dichos patrones, a raíz de la introducción de la televisión con contenidos en su mayoría de factura estadounidense. Su estudio médico antropológico mostró insatisfacción corporal en varias mujeres que antes aceptaban sus cuerpos de anchas caderas, abundantes pechos y narices abultadas y registró una necesidad de modificarlos y adaptarlos al patrón de mujer estadounidense (Becker, 1998).

\section{El espejo de los medios}

Los medios son espejos en donde se ofrecen imágenes corporales que relacionan ideas de belleza con vidas de éxito, y en este espacio se presentan investigaciones cuyas herramientas etnográficas de observación y registro buscan describir, interpretar, desentrañar estructuras de significación para analizar construcciones culturales a partir del cuerpo proyectado. 
Lo simbólico tiene una existencia tan concreta y una entidad tan manifiesta como lo material y sus estructuras están sobrepuestas, entrelazadas y muchas veces invisibles y difícilmente decodificables.

Los estudios que a continuación se presentan ofrecen ejemplos de discursos mediáticos autoritarios que se manifiestan en tendencias homogeneizantes de imágenes corporales marcadas por el género y que son profundamente antidemocráticas:

¿Acaso nuestra pluralidad de razas, etnias, clases sociales, está representada en la imagen corporal que ofrecen los medios y la publicidad? ¿Acaso se ofrece la diversidad de tallas cuando se define la belleza? ¿Cuáles son los patrones de inclusión-exclusión cuando de imagen corporal se trata? ¿Cuáles son las disciplinas de adaptación a patrones hegemónicos de belleza y éxito?

\section{Género e imagen corporal}

Es necesario partir de la categoría género, que como construcción social y física del sexo, plantea una manera nueva de revisar viejos problemas (Lamas, 2002: 38).

En el estudio de los medios masivos de comunicación, el problema de la dominación y el poder de los medios se vaticinó durante las primeras décadas del siglo XX por los teóricos de la Escuela de Frankfurt. El asunto de la globalización mediática vio su semilla en los trabajos visionarios de Mc Luhan durante el decenio de 1960, y los trabajos de Dorfman y Matellart, quienes desde 1971 registraron los peligros de la colonización cultural en la figura de Mickey Mouse y su transnacionalización.

Los estudios de género, por su parte, hicieron uso de estos y otros marcos para delimitar con claridad y precisión las diferencias que se establecían en los medios cuando de mujeres y hombres se trataba. Se detectaron y denunciaron desigualdades, esencialismos y opresión, invisibilidades y ausencias en contenidos informativos, programas femeninos y de entretenimiento, en donde se registraba la permanencia de oposiciones binarias y estereotipos.

Con respecto al concepto de imagen corporal, la categoría género ayudó a detectar algunas implicaciones. Por un lado, que describe un espacio en donde cuerpo, mente y cultura se intersectan, es el cuerpo, como construcción cultural, un sitio crucial para la producción de categorías de género, los valores, actitudes y juicios que sobre éste, sexuado, producen los medios y que nos educan en lo que debe ser un cuerpo socialmente aceptado. Su análisis aporta claves para la comprensión de las diversas redes de poder que refuerzan los medios. 
Por otro lado, debe distinguirse entre imagen corporal como producto de la imaginación, que no debe confundirse con el cuerpo físico o la imagen que el cuerpo proyecta hacia fuera. Esta situación puede darse, pues se ha creado al amparo de los medios electrónicos e impresos que promueven la confusión entre imagen y realidad.

El cuerpo está ahí en su materialidad y la imagen es la interpretación de esa materialidad. La traducción del cuerpo físico en imagen corporal implica un proceso complejo sujeto a distorsión, que define lo femenino y lo masculino, ambas construcciones de género que por lo general devalúan lo femenino a través de estereotipos y dicotomías que desde la infancia se inscriben en la personalidad.

Lo anterior se da, por ejemplo, en las maneras peculiares en que los familiares y amigos se relacionan con nuestros cuerpos desde la infancia y mientras crecemos, las maneras que nos definen en la escuela y en el trabajo con calificativos, dichos populares, piropos, chistes, etiquetas que permanecen grabadas en la memoria.

En ese mismo sentido, son los valores trasmitidos otrora por la familia, la Iglesia y la escuela y la comunidad, y que se trasmitían de padres a hijos y que han sido reemplazados por imágenes mediáticas que reconfiguran y transforman valores con una velocidad sin precedentes en todos los estratos sociales y geografías.

Las imágenes corporales que trasmiten los medios son reguladas por grandes consorcios y modificados digital y quirúrgicamente para transformarlos y adecuarlos al ideal de belleza cuyas consignas se registran, por ejemplo, en las páginas de la revista $T V y$ Novelas de Editorial Televisa, líder del mundo del espectáculo, cuyo tiraje manifestado es de 550 mil ejemplares semanales, dirigido a un perfil de "mujeres solteras y casadas, entre 13 y 34 años, estudiantes, amas de casa con hijos, dedicadas al hogar, nivel educativo medio y bajo" (Directorios publicitarios, mayo de 2002: 255), o bien: "El cuerpo es tu tarjeta de presentación", "quítate esos kilitos de más", "la belleza cuesta", "como te ven te tratan", "ya es posible corregir esos defectos de la naturaleza" (TV y Novelas, 15 de julio, 2002).

El álbum fotográfico de Thalía, quien se ha sometido a ocho operaciones de cirugía plástica y una de extracción de costilla (aunque ella lo niega), es ofrecido con el siguiente encabezado a los lectores de la revista ( $T V$ y Novelas, 18 de junio, 2002): "Poco a poco con ayuda de la cirugía ha transformado su rostro siempre bello para quedar más guapa (su última operación: la nariz)".

Según Tolman y Debold, el concepto imagen corporal sostiene la tensión de una escisión prevaleciente en la cultura occidental entre experiencias del cuerpo y convenciones de la mente. Al recordar las diferencias entre cuerpo e imagen, ambas nociones entran en conflicto (en Fallon, 1994: 310). 
Pero, ¿qué significa tener un cuerpo? El cuerpo vive y palpita; al ruido de una puerta que se abre, responde con piel de gallina que le recorre; un corazón que late anticipando una caricia; el grito que constata la presencia del dolor; el miedo que paraliza la garganta; la humedad de la pasión; la sensación de hambre; el olor inconfundible de un ser querido. Vivir dentro de un cuerpo significa sentir miedo, hambre, dolor, ansiedad, frustración, placer.

Por otro lado, ¿qué es una imagen? Una imagen se crea cuando alguien mira. Es aquello que se forma en la retina cuando se mira. Una imagen no tiene sentimientos, es plana, es silenciosa, no tiene poder en sí misma; crea un cuerpo sin cuerpo, un "cuerpo de nadie" porque existimos no en imágenes que reflejan los deseos de otros, sino en cuerpos materiales (op. cit.: 153).

Hablar de imagen corporal es tratar de comprender la relación del sujeto con su cuerpo y las complejas redes de poder que se tejen en su entorno. Este artículo presenta algunos estudios que sugieren diversos abordajes para su análisis.

\section{Modificaciones del cuerpo, televisión y publicidad}

El estudio de Groz sobre modificaciones del cuerpo en televisión y publicidad llama metáforas de inscripción sobre el cuerpo a los rótulos sociales que éste ha portado a lo largo de la historia. Frente a lo que Foucault llama "superficie rotulada de eventos", opone ella una imagen elástica y no estática, sustancia concreta o concepto fijo culturalmente, que adquiere forma solamente a través de su inscripción cultural.

El cuerpo se torna plástico cuando se inscribe en el género y en las normas culturales. Mientras que Foucault asume la existencia de un cuerpo preinscrito, Groz argumenta que no hay acceso posible a un cuerpo que no haya sido interpretado socialmente de manera previa. La constitución del cuerpo descansa sobre su inscripción y se convierte en el texto que se escribe sobre él y del cual puede diferenciarse. Aquí se discute la metáfora de dicha inscripción, al contemplar imágenes homogéneas de cuerpos como resultado de implantes, cirugías cosméticas, dietas, gimnasia reductiva en programas de opinión, reality shows, telenovelas en televisión y publicidad.

Mientras algunos teóricos rechazan el cuerpo pre-inscrito, los discursos populares que promueven el cambio del mismo asumen la existencia de un cuerpo anterior a estos procedimientos electivos y refuerzan la dualidad cuerpo-mente sitiada.

Brush describe cómo los discursos de modificación corporal refuerzan la disciplina inscriptiva e impone grados de inscripción literal y figurativa. Al yuxtaponer estas dos perspectivas explora cómo ambos discursos destruyen la materialidad del cuerpo y los contextos sociales en los cuales viven y construyen. 
Mientras que la retórica que rodea a dichas inscripciones quirúrgicas, cosméticas y aeróbicas niega el proceso físico y las restricciones económicas, así las teorías sobre el cuerpo que enfatizan su plasticidad niegan la materialidad de dicho proceso y los contextos sociales y culturales en donde se sitúa el cuerpo.

Para profundizar en el análisis se sugiere entrevistar a especialistas-médicos cirujanos plásticos, profesores de educación física, creativos de agencias de publicidad, entre otros, con preguntas sobre criterios de selección de modelos y contenidos así como conceptos de femineidad, belleza, atractivo. Además pueden registrarse conversaciones sobre dichas temáticas en salones de belleza, clínicas de estética femenina, gimnasios, clubes deportivos, reuniones familiares, reuniones con amigas-amigos.

El estudio de Klesse presenta el análisis de documentos históricos de diferentes épocas en donde se explora la filosofía de los "modernos primitivos" que buscan inspiración en las técnicas de modificación corporal y los rituales de las llamadas sociedades primitivas. Al comparar diferentes etapas de la historia fija, los ejes analíticos cuerpo, sexualidad, comunidad y espiritualidad se conciben como oponentes radicales percibidos como tales en la modernidad occidental, los cuales se mantienen cautivos en supuestos discursivos fundacionales.

Argumenta que el movimiento que buscó recuperar el "primitivismo" representa una estrategia identitaria particular en la condición moderna. Mediante el análisis de contenido mediático intenta interpretaciones en torno a la autoimagen occidental. La noción de lo primitivo se observa en el legado poscolonial como "la otredad" cuya tradición inevitablemente reproduce estereotipos de raza.

\section{Construcción de la belleza en revistas femeninas}

Por medio del análisis de contenido, Eskes, Duncan y Miller discuten revistas femeninas a la luz de la ecuación "salud física y belleza" que éstas prometen. Conceptos de Foucault sobre poder y disciplina y de Marcuse sobre cooptación se emplean para conformar el cuerpo teórico de la investigación.

Se exploran los mensajes y significados en torno al concepto "belleza" y "cuerpo atractivo", vinculados con modificaciones físicas, y su relación con el mensaje publicitario, que incluye nociones de apoderamiento, igualdad y libertad. Al hacer esto manipulan a las lectoras a concentrarse en sus cuerpos físicos y, contradictoriamente, ofrecen mensajes de libertad y autonomía. Lo anterior reditúa socialmente a las lectoras en los terrenos de la aceptación y prestigio, pero pone en peligro en varias ocasiones su salud.

Se realizan monitoreos de anuncios publicitarios en televisión y revistas femeninas de medicamentos para adelgazar o desvanecer las várices, cremas 
para "blanquear" la piel, productos para "corregir defectos físicos" en nariz, piernas, abdomen, busto, y asimilar dichos cuerpos a patrones de belleza establecidos.

Para profundizar sobre el tema se sugieren registros de conversaciones cotidianas en salones de belleza, parques, deportivos, clubes, institutos de belleza, discotecas y fiestas.

Televisión, cine y rituales familiares

Liuccio monitorea escenas televisivas y cinematográficas relacionadas con comida en los medios y afirma que las anomalías alimentarias de la época actual son causadas por un quiebre en las costumbres y normas en torno al comer.

Registra tiempos y ritmos de la ciudad en aquello que llama la "prisa moderna", que es descrita en sus diferentes facetas por los medios en escenas que desvanecen algunas formas ancestrales de la comida en familia.

Juega con la etimología griega de la palabra gastronomía -manifestación de gastro y anomia - y analiza trastornos alimentarios, como comedores compulsivos, obesidad, anorexia y bulimia; distorsiones sociales de la imagen corporal a la luz de cambios en patrones familiares durante las comidas; la creciente popularidad de comidas rápidas y lugares que las ofrecen. Estos nụevos hábitos alimentarios eliminan las oportunidades convivenciales en lo que registran los historiadores como el ideal de la familia burguesa.

\section{Medios y presión}

Diversos estudios han probado que las presiones socioculturales han sido consideradas fuente principal en trastornos de la imagen corporal, y en particular los medios, con el énfasis en la extrema delgadez como norma del atractivo femenino (Heinberg y Thompson, 1995).

Irving también informa que las mujeres perciben a los medios como fuente de presión para ser delgadas, ya que al ser expuestas a modelos de mujeres menos esbeltas, la presión disminuye, y entre más expuestas estén a los medios, más son proclives a adquirir síntomas de trastornos alimentarios.

$\mathrm{El}$ estudio registra más comparaciones en mujeres que en hombres con respecto a las imágenes mediáticas y a su grupo de amigas. Se percibe discrepancia entre su atractivo personal y la norma mediática, y la investigadora sugiere un programa de "alfabetización mediática" en la que se eduque a los receptores a volverse consumidores críticos de modelos poco realistas y trucados tecnológicamente.

Otro estudio examina tres tipos de agentes socioculturales que, combinados, influyen en la insatisfacción corporal y la restricción dietética de mujeres 
adolescentes: padres, amigos y medios (Tracy, 2001: 43). Los resultados prueban que aquellas con mayores índices de insatisfacción y restricción dietética viven la subcultura que las promueve.

Algunos investigadores como Levine y Smollack atribuyen un papel mayor a los medios, ya que ha habido una tendencia a lo largo de las últimas décadas para estimular el ideal femenino de la delgadez, a pesar de que se han registrado aumentos generales en la talla femenina de las mujeres en contextos anglosajones.

Este estudio reporta la evaluación sobre tres intervenciones, diseñadas para evitar que las mujeres se sientan perturbadas al ser expuestas a los medios.

Con ayuda del instrumento llamado "inventario de imagen corporal" y de "cambio corporal", asi como un cuestionario de preguntas abiertas, Mc Cabe analiza la naturaleza de la imagen corporal y las estrategias de cambio corporal en Victoria, provincia canadiense. El sondeo quiso determinar las influencias socioculturales de dichas variables entre 1,266 adolescentes y mostró que la mayoría de ellas estaban menos satisfechas con sus cuerpos y podían adoptar estrategias para perder peso, mientras que los hombres podían adoptar estrategias para aumentar tono muscular y peso corporal.

Se comprobó que la influencia de los medios era más importante en las mujeres, así como la presión de los padres y los amigos. Se registró además que los padres eran claves en trasmitir mensajes socioculturales a los adolescentes sobre el ideal corporal.

Además reveló que las mujeres reportaron mayor influencia de ambos sobre la apariencia de sus cuerpos y ellas también mostraron mayor influencia de sus padres hombres. Igualmente, se mostró mayor influencia de medios, en especial revistas femeninas sobre la imagen corporal, aunque no se ha investigado la imagen corporal masculina.

\section{Rituales y cuerpo bello en aeróbicos}

Maguire y Mansfield examinan los rituales conductistas y emocionales de mujeres en clases de aerobic en la región central de Gran Bretaña, utilizando la técnica de observación participante y entrevistas en lo que llaman el complejo espacial "ejercicio-cuerpo-belleza. Según ellos se trata de una red de género que aglutina y disciplina; sus objetivos son indagar sobre el conjunto de restricciones sociales, y el autocontrol, que se entrelazan con el manejo racionalizado del cuerpo femenino. Se registran las experiencias sobre el cuerpo y desde el cuerpo de las mujeres, que a su vez muestran rasgos restrictivos y coactivos a largo plazo. Dicho complejo "ejercicio-cuerpo-belleza", como fuente encubierta de desapoderamiento, refuerza las normas, al tiempo que realinea imágenes dominantes sobre femineidad que promueven 
rasgos supuestamente liberadores y que en realidad constriñen y disciplinan el cuerpo.

\section{Cuerpo "adecuado"}

Sassatelli analiza la cultura del "cuerpo adecuado", adaptado a la norma social, no como colección de imágenes comerciales o como producto de valores culturales de gran alcance, sino como un conjunto de prácticas corporales que se llevan a cabo en instituciones creadas para la reinterpretación de las mismas, como son gimnasios, clubes, centros recreativos.

Se apoya en observación participante y en entrevistas con el personal que labora en dichas instituciones en Florencia, Italia, así como en diarios y revistas sobre el tema.

Concluye que los gimnasios están definidos como espacios para el placer y la relajación, sitios con reglas propias y juegos de identidad. El ideal del cuerpo se filtra a través de sus cargas de género y clase social, trasformado como un instrumento de entrenamiento, una máquina que no se parece al cuerpo orgánico y como una mercancía objetivada más allá de cualquier rol especificado de género. Éstos fungen como requisitos sobre el cuerpo de los miembros potenciales para marcar la pertenencia al espacio o su exclusión.

De manera similar, el ideal cultural del cuerpo adecuado y tonificado contribuye a la legitimación del espacio, aunque la capacidad para entrenar es menos importante que el resultado de la cultura que se ofrece. No se imponen definiciones del cuerpo, pero se negocian y se transforman constantemente dentro de los límites que marca la norma.

\section{Cuerpo deportivo}

Markula intenta reconstruir el diálogo cultural en torno a la imagen corporal femenina en los deportes aeróbicos, echando mano de trabajo etnográfico, como son entrevistas con deportistas y análisis de televisión, revistas, periódicos, fotografías y publicidad. Describe el ideal mediático de la mujer aeróbica y los resultados indican su carácter contradictorio: "firme pero torneada", "deportista pero sensual", "fuerte pero delgada".

Asimismo, la relación de las mujeres con su imagen mediática se vive como contradictoria, ya que luchan por obtener el "cuerpo ideal" y simultáneamente encuentran ridícula la batalla.

Las interpretaciones muestran cómo el discurso que rodea a la imagen corporal femenina es parte de un uso complejo del poder sobre las mujeres en la sociedad de consumo posmoderna. Se reflexiona desde la perspectiva feminista sobre el papel que le asignan al deportista como individuo, al 
cuestionarle la situación de poder en la que está inmerso y en el potencial que tiene para contrarrestarlo. ¿Cómo puede responder el atleta que se convierte en cartel publicitario ambulante, como es el caso de futbolistas, velocistas y clavadistas que anuncian Nike, Adidas, McDonalds en sus prendas deportivas? ¿Cómo puede defender su vida privada de los depredadores medios que lo persiguen sin misericordia?

\section{Fisicoculturismo femenino}

Heywood explora el mundo del fisicoculturismo como metáfora para el lugar que las mujeres ocupan en el clima político y cultural actual. Analiza los medios y entrevista a personas en el movimiento para afirmar que el fisicoculturismo está entrampado entre corrientes culturales competitivas.

$\mathrm{El}$ deseo de convertirse en un híbrido monstruoso - seres extraordinarios con proporciones masivas - y los requisitos de femineidad asignados al género, son las contradicciones que se discuten en el discurso sobre "cuerpo perfecto" al interior de grupos que practican dicho deporte.

Lo curioso es que ha llegado a practicarse masivamente en algunos lugares de Europa y EE.UU. a fines del decenio de 1980 y durante el siguiente, cuando el reto al cuerpo convencional femenino estaba en su apogeo. Sin embargo, a mediados del decenio de 1990, una revisión al feminismo replanteó las ideas sobre belleza en el cuerpo femenino y se le dio preferencia a los cuerpos femeninos que eran menos monstruosos y más apegados a las imágenes convencionales de femineidad.

A la larga, los fisicoculturistas empezaron a representarse menos como atletas y competidores que como imágenes sexuales. Eventualmente esto llevó a una noción más generalizada de cuerpo deportivo. Heywood examina esto en material fotográfico, afiches, carteles y representaciones raciales, así como por medio de entrevistas en clubes deportivos, gimnasios, etcétera.

\section{Dicotomías del cuerpo}

Fouts califica el cuerpo como natural-no natural con relación a las construcciones sociales sobre identidad genérica. Se analizan las tecnologías del cuerpo, por ejemplo, la cirugía estética femenina como acto de crear un cuerpo con partes artificiales al estilo Frankenstein.

Como práctica extrema, este espacio corporal se usa para naturalizar y legitimar el poder patriarcal a través de adaptaciones del cuerpo imperfecto al cuerpo perfecto, engendro de Barbie: caderas estrechas, busto abundante y perfil de niña. Pretende mostrar relaciones de género codificadas a través del cuerpo, por medio de entrevistas con mujeres adolescentes en escuelas secun- 
darias, salones de belleza, clubes y gimnasios, para analizar las maneras en que el cuerpo puede mantener la opresión en las mujeres, aunque, por otra parte, se registra también cómo el cuerpo femenino ha ejercido el potencial que tiene de desestabilizar, resistir o transgredir las normas de género y sus construcciones de poder.

Falta analizar las trasgresiones que en ese sentido y desde el cuerpo femenino han realizado Yuri (versión mexicana de Madonna), Gloria Trevi (linchada mediáticamente) y Alejandra Guzmán, como intentos de libertad sexual en su momento. También es necesario reflexionar sobre la trasgresión que logra Jennifer López como nuevo ícono de belleza latina: anchas caderas y glúteos prominentes, evocaciones de pasados ídolos eliminados por las esbeltas de fin de siglo.

\section{Estereotipos étnicos eternos}

En otras latitudes, Gardner examina los medios a la luz de tradiciones japonesas de artificialidad y superficie, con respecto al ideal femenino, y los articula a partir del discurso posmoderno de consumo y deseo, ver y ser visto, deseo y miedo.

Japón es visto en Occidente como el lugar de lo exótico: la geisha, el samurai y el zen simbolizan lo exótico e incomprensible y son símbolos de identidad nacional-parte integral de las teorías de unicidad y superioridad inherentes a la mitología nipona.

La belleza femenina oriental ha sido una constante en el estereotipo de objeto de deseo y enigma -aplicación de polvo blanco, pasta que ennegrece su dentadura, labios rojos- y ha permanecido lejos de otro estereotipo, el de las damas francesas de la corte de Luis XVI con permanentes, cabello teñido y botas de plataforma.

En la búsqueda de estereotipos femeninos y apuntalada por la imagenología del siglo XVIII, la investigación de Chew acude a los archivos históricos para registrarlos en relatos de viaje estadounidenses.

Los viajes son una medida de la capacidad expansiva y aventurera del ser humano. Según estos recuentos, los franceses se describen como poseedores de un "aura de sexualidad audaz", comparada con las predilecciones más bien calvinistas de los angloparlantes.

A fines del siglo $\mathrm{XX}$, los franceses acudían al cine sólo para ver los comerciales. Esto no sorprendía en una cultura que "desenfadadamente" exponía los pechos de las mujeres en el dinero, como es el caso de la pintura de Delacroix impresa en un billete de 100 francos.

Al mismo tiempo, en 1988 aparecía en EE.UU. una estampilla celebrando el bicentenario de la Revolución francesa con la misma pintura, aunque ocultando el pezón que "lascivamente" aparecía en la versión original. 
Mientras que el origen último de dichas interpretaciones fallidas debe ser trazado al amparo del impacto que causó la reforma religiosa a favor de la austeridad sexual, los primeros contactos con los franceses registraban al final del siglo XVII una existencia de la "lujuriosa Luisa" de origen francés, vista y censurada por la "Susana austera" estadounidense. Su crítica sobre la moral francesa percibida como "liviana" se centraba en el carácter de la mujer francesa, la institución de la amante y la sexualidad de la sociedad en su conjunto materializadas en el arte, en el teatro, en el ballet, en la diversas modalidades de diversión.

Es interesante notar la prevalencia de esos estereotipos en los medios electrónicos que siguen presentando los mismos clichés regionales. Interesante sería explorar si la moda latinoamericana actual en Hollywood ha podido trastocar los estereotipos de la mujer mexicana que el cine marcó durante su época de oro.

\section{Imagen corporal y autoestima}

Cusamano y Thompson elaboran una escala multidimensional que mide la influencia de los medios sobre imagen corporal. El instrumento se aplicó a 75 niños y 107 niñas entre 8 y 11 años de edad, y fue diseñado para evaluar cinco facetas de influencia de medios, previamente conceptualizadas por los investigadores. Resultaron tres escalas que abarcaron conceptos definidos como internalización, conciencia y presión.

Mostró una mayor incidencia de insatisfacción corporal en las niñas.

Los resultados se discuten a la luz de la utilidad de dicha escala y el papel de la internalización como factor de riesgo para el desarrollo de distorsión de la imagen y su incidencia en trastornos alimentarios.

\section{Cuerpo y pornografía}

Ullen relaciona el género con la pornografía y el consumismo. El consumo de medios como práctica voyeurista de la recepción tiene como objetivo último el consumo, según el mandato mercadológico. Los anuncios publicitarios promueven el mito de que todo deseo puede satisfacerse inmediatamente, como la pornografía y su promesa de gratificación sexual instantánea en tanto excitación inmediata del deseo.

Los anuncios nos instruyen a comprar, pero, ¿qué compramos?, ¿cuál es el significado de las historias en las que participamos como consumidores?

Registra la complicidad entre ambos, publicidad y voyeur-consumidor, en la objetivación del cuerpo femenino, en el monitoreo que realiza de la televisión sueca para mostrar la condición reemplazable de la mujer invocando la 
imagen fálica de la pornografía al cargar el acto de consumir con implicaciones ideológicas. Más que vender un producto, la publicidad vende un mito vinculado con la experiencia-promesa pornográfica.

\section{Revistas y el cuerpo europeo}

Desde el decenio de 1950 Marie Claire, Biba Prima y posteriormente Elle son revistas femeninas que exitosamente han lanzado representaciones de femineidad proveyendo un discurso visual del ideal europeo. Ofrecen conocimientos sobre cuerpos femeninos a sus lectores que, a diferencia de otros títulos en el mercado, basan su discurso en su identidad regional, que podía no sólo existir en Gran Bretaña, sino que forma parte de los nichos transnacionales de mercado habitados por mujeres de la comunidad europea e internacional.

Privilegiar las imágenes de la mujer europea descansa en dos factores: el primero, como resultado de nuevas formas de estilos de vida transnacionales que han desarrollado nuevos conocimientos y prácticas en torno a la mercadotecnia y la publicidad. El segundo, como producto de transnacionalización de la imagen corporal europea de dichas revistas y la flexibilidad y eficiencia creciente en torno a las publicaciones de revistas en el viejo continente.

\section{Tribus mediáticas y solidaridades}

Maffesoli reflexiona sobre la fragmentación y reescritura de la noción de solidaridad en la vida cotidiana a la luz de una serie de monitoreos en televisión. Argumenta que las categorías modernistas y las narrativas fundacionales que explican, y por eso refuerzan el orden social de los estados nación, se enfrentan a retos profundos.

Analiza grupos pequeños y agrupaciones temporales de seres humanos y sus miembros a diferentes horas durante el día. Observa que las situaciones grupales o tribus tienen algún grado de autoconciencia y estabilidad como ingrediente central, y son el hecho social clave de la experiencia diaria de la vida.

La cultura de masas ha desintegrado la existencia social y ha fragmentado las agrupaciones tribales en nuevas organizaciones en torno a palabras clave, nombres de marca y bites de cultura de consumo.

A pesar de ello, las tribus tienen un enorme poder de solidaridad grupal. Sin embargo, en medio de las manías de moda se enraízan nuevas formas de colectivos sociales y retan modelos establecidos de morales tradicionales. También emergente, se encuentra el arte de llevarse bien para mantener la solidaridad de la tribu y facilitar la diaria interacción.

Más allá de las cuestiones sobre derechos universales acerca del bien y el mal, uno trata con asuntos de "adecuación" y adaptación a las situaciones. 


\section{Armaduras corporales}

La construcción de la identidad femenina a través de la publicidad en el uso de ropa, maquillaje y adornos se vincula al consumo y su relación con el cuerpo. La articulación entre consumo, vestido e identidad, a partir del cuerpo, se explora en un estudio sobre la práctica femenina de "ir de compras" y la búsqueda de vestimenta en donde se problematiza la adopción de atuendos como parte del habitus de género y generacional a partir del análisis de artículos en revistas y programas de televisión que refieren discursos femeninos en torno a la madurez y/o disponibilidad sexual a través del atuendo.

Paralelamente, se discute el discurso feminista que reta la sexualización de niñas y mujeres jóvenes a través del vestido. En el contexto inglés urbano, Frith y Gleeson exploran vínculos entre medios masivos de comunicación e historias femeninas que comparten la preocupación por rescatar a mujeres jóvenes de depredación sexual por medio de una vestimenta "protectora".

Las autoras exploran los discursos sobre el ocultamiento-simulación de la figura femenina frente a la atención sexual no deseada y la presión que ejercen sobre ellas las restricciones en su manera de vestir. Analiza el impacto que esto tiene sobre los intentos juveniles de desarrollar y presentar identidades maduras. En este sentido, la apariencia se vuelve lugar de negociación sobre la consolidación de identidades adultas y la autonomía y control que éstas conllevan.

Este trabajo aborda las tensiones entre las metas de los adultos frente a las de los jóvenes, y analiza sus discursos en competencia, que las autoras definen como proyectos de identidad en colisión. Algunos jóvenes interpretan el discurso de "protección en contra de la depredación" como estrategia para prevenir o retrasar la independencia y autonomía a través de formas conservadoras en el atuendo.

El consumo de ropa se analiza desde el género como arena de lucha por el control y definición de la identidad, y se articula con otros ámbitos, como son la selección y aplicación de maquillaje, el uso de adornos y otros aspectos de la apariencia.

La vestimenta es también objeto de estudio para Kennedy, quien concibe las tallas corporales como formas de reconocimiento de identidades. Son el punto de partida para el trabajo de campo en tiendas de ropa en donde la autora observa y registra la relación cuerpo-talla, experiencia común en mujeres británicas, no así entre los hombres.

A través del estudio de prácticas comerciales discursivas —publicidad, precios, designación espacial y clasificación de ventas al menudeo-, registra las normas con relación a la talla y la apariencia personal, consolidando un discurso sobre la normalidad-anormalidad. 
Los almacenes etiquetan las tallas con números y tamaños "petite" (pequeño), "extra grande", "plus", para describir los tamaños de los cuerpos de mujeres y sus dimensiones grandes y pequeñas, así como las tiendas que ofrecen espacios distintivos para vender ropa con tallas grandes. Analiza la ideología de género que subyace en dichos sistemas de vestimenta y tallas, así como sus efectos en las experiencias de mujeres con tallas fuera de la norma. A pesar de los efectos poderosos de interpelación que dichos mensajes conllevan, esta investigación reporta que las mujeres de tallas grandes parecen evitar el juego de la clasificación numérica.

La autora contempla esto a la luz de su potencial subversivo frente a las construcciones culturales en torno a los cuerpos de las mujeres y la normatividad.

Poco se ha estudiado el sujeto consumidor de modas, afirma Colls, y explora las experiencias espaciales y corporales de las mujeres en la práctica del consumo de ropa. Articula cuerpo, geografía y consumo, interesado particularmente en la comprensión sobre los significados del "cuerpo de moda" y en las relaciones que vinculan a éste con los atuendos y espacios destinados para el consumo y su normatividad.

Por medio de observación directa y grupos focales de mujeres, registra en primer lugar las menciones en torno al cuerpo en diferentes situaciones: los cuerpos "dentro de la ropa" y las observaciones que hacen las mujeres sobre las texturas de sus cuerpos en contacto con la ropa.

En segundo lugar, registra su relación con el cuerpo "pasado y presente" y menciones sobre pérdida de peso, aumento, menopausia, maternidad, embarazo, y, en tercer lugar, las negociaciones que ellas realizan con los espacios de consumo de ropa con relación a sus "inversiones" en moda y vestido, tales como talla, conocimientos populares sobre moda, representaciones de vestidos en los cuerpos.

La ropa establece fronteras espaciales con énfasis en hegemonía étnica, y la moda produce, reproduce y significa a través de su capacidad de legitimar, "dar cuerpo" a las prácticas de consumo.

\section{Publicidad y piel}

Curtin analiza las implicaciones de las tecnologías de la piel en la industria deportiva de cara a los juegos olímpicos de verano. Atuendos tejidos a mano, vestuarios especiales para la velocidad que "suavemente oprimen el músculo", son segundas pieles creadas por Nike en su campaña publicitaria llamada "La evolución de la piel."

El ímpetu detrás de estos desarrollos sofisticados de la moda atlética y deportiva ha transformado el vestuario deportivo en atuendo performativo que oscila entre materiales reciclables y diseños de una armadura corporal 
que "previene exceso de vibración y desperdicio de energía", según un boletín de Reuters.

El mundo del diseño atlético hace predicciones culturales con la promesa de evolucionar la piel. El nudismo resultante de Nike inaugura simulacros epidérmicos en una promesa que trasciende utópicamente raza y género. Los consumidores han invertido 200 millones de dólares en la compra de materiales performativos, que incluyen un sistema que elimina lo "abyecto" del cuerpo, tal como dice el texto: "No se trata sólo de moda, es no tener que vestir tu propio sudor." La exposición continua a los elementos pone en riesgo a los atletas en su retorno al primitivismo, como se lee en el torso del futbolista Ronaldo, cuya vulnerabilidad "humana" es invocada en este texto: "Puedes ser un toro, un tren, un acto divino, pero estás protegido sólo por la piel que se te dio cuando naciste."

En otro anuncio la fragilidad femenina se articula en el siguiente texto: "Esto es acerca de la piel (suave) y la tierra (dura, mojada, cortante, fría)." Los significantes en paréntesis se aglutinan en una formación que interrumpe la sintaxis: la tecnología protege y contrarresta la "brutalidad" del mundo. Para sobrevivir a los compromisos de la receptividad del cuerpo femenino, se recomiendan atuendos de alta tecnología que suplantarán la piel y proveerán de otra nueva para la competencia.

Sin embargo ésta no deberá arriesgar el habitus de género al presentar demasiada agresividad que desestabilice la categoría de lo femenino sobre la cual dependen las teorías evolucionistas.

\section{Turismo y cuerpo}

La sociología apuntalada por la teoría feminista ha ayudado a legitimar el estudio de espacios recreativos. En este sentido, las manifestaciones de género en torno a la imagen corporal, respecto a la determinación del bienestar y la salud como aspectos de la identidad femenina, han iniciado la teorización en torno al cuerpo en los estudios sobre turismo y género de Aichinson y Jordan.

Aquí también se discute sobre la mirada turística a partir del concepto foucaultiano de "disciplina del cuerpo" para comprender la tríada turismo-género-generación. Existe poco reconocimiento del papel que esta relación ha desempeñado en el consumo productivo del cuerpo hegemónico en ámbitos recreativos en lo que se refiere a habitus turístico: vestimenta, rutinas, alimentos, paseos, territorios, etcétera.

Por un lado, se han cuestionado las construcciones idealizadas de femineidad y cuerpo femenino que presentan las industrias que las promueven -agencias, publicidad, aerolíneas, representantes de moda y diseño de moda, 
música popular y medios masivos de comunicación-, pero esto no ha sucedido con las nociones hegemónicas de "cuerpo deseable" que implican.

El turismo se alimenta de su imagen y como fenómeno expansivo juega un papel en la estructuración de identidades, lugares y gente, conformando cierta tipología de mujeres y hombres que ejerce una influencia sobre su público como consumidor potencial de turismo. Las autoras evalúan discursos sobre cuerpo-turismo a la luz del análisis de 50 revistas femeninas y exploran en grupos focales de mujeres involucradas en ciertas prácticas en clubes deportivos y áreas recreativas públicas y privadas.

\section{Cuerpos ejemplares}

Hodgson señala que la difusión en Gran Bretaña de revistas recientes especializadas en la celebración de la disciplina corporal resulta en consejos para imitar el ideal de belleza en tanto reducción de tallas. Tal es el caso de Cuerpos de Celebridades, revista que estimula la preparación de los cuerpos mediante una disciplina reductiva de dietas y ejercicio. Su editora Alison Hall afirma que, debido al éxito, su publicación será mensual y no bimestral, como estaba planeada.

Las "vidas ejemplares" modernas no son ya vidas ilustres de santos, personajes de la realeza, políticos destacados, héroes míticos, sino cuerpos..., semblanzas de vidas de actrices y modelos que, como Geri Haliwell -ex integrante de las Spice Girls-y Jennifer Aniston - la actriz mejor pagada de la serie televisiva Friends-, se vuelven célebres por su disciplina en la reducción de tallas.

El primer número da recetas para imitar a Aniston, quien redujo tres tallas en poco tiempo. Mientras que la secretaria del Ministerio para las Mujeres, Tessa Jowell, criticó acremente su aparición, la editora de la revista afirmó que aportaba una gran gama de dietas nutritivas a sus lectoras.

Otra vida ejemplar es el caso de Britney Spears, admirada por niños, jóvenes y adultos por su cuerpo gracioso y dinámico y su forma de bailar. Ella sufrió un desmayo durante un ensayo en el Foro Sol de la Ciudad de México, por haber sido sometida a una dieta rigurosa de agua y verduras para bajar "esas llantitas tan desagradables", según reza una nota del diario Reforma del 19 de julio de 2002. La razón por la cual rompió la regla de la dieta es la reciente separación de su pareja. Ella, como Aniston y Halliwell, es ícono de belleza y éxito, pero también parece tener una vida propia.

Spears fue duramente atacada por los medios mexicanos por ejercer su derecho de no responder a preguntas sobre su vida privada. Con ello rompió otra regla, la de sumisión ante la prensa amarillista. 
Cuerpo invisible: el ama de casa

Click analiza el consumo de la perfección de prácticas femeninas convertidas en mercancía a través del fenómeno Martha Stewart en EE.UU.

Atuendo sobrio pero casual, y suavidad de movimientos, hacen de la imagen corporal de Martha Stewart emblema de la mujer madura estadounidense, quien publica en 1982 un libro sobre cómo servir una "mesa de café" y en 2001 dirige un emporio que incluye, además de doce libros que encabezan las listas de libros más vendidos, dos programas de televisión, dos revistas, una columna diaria en prensa, una página web, un programa de radio y una línea de productos en las tiendas K-Mart.

Ha sido de considerable impacto en la cultura estadounidense el nombre de Martha Stewart, empleado frecuentemente como adjetivo, sinónimo de perfeccionismo obsesivo en el cuidado del hogar y la familia. Sus recomendaciones y consejos estimulan modas y tendencias en el decorado de los hogares, diseño, restauración, jardinería e industrias culinarias, cuidado de mascotas.

Como objeto de amor y odio, ella ha creado un emporio que ha cultivado a millones de seguidores. La autora articula los estudios culturales con la investigación de la comunicación de masas y la teoría feminista para arrojar luz sobre el significado en la cultura popular estadounidense del fenómeno Martha Stewart, tanto en los productos que ha generado como en un estilo de vida en la recepción de los mismos.

La autora se plantea preguntas sobre los componentes de sus mensajes y productos que resuenan en su público y asegura que además de proporcionar mero entretenimiento, confiere mensajes sociales de género sobre la "propiedad" de los roles femeninos tradicionales y la conservación y reafirmación de los mismos a lo largo del tiempo.

El paradigma de género que atraviesa generaciones es socialmente buscado y reforzado, ya que eleva el estatus social y de clase y con ello refuerza un papel que sigue vigente en la sociedad estadounidense. Son varios los elementos que relevan el epítome de femineidad, que renueva esencialismos sobre generosidad y buen gusto: siempre estar "lista" para "atender a los demás, "su generosidad" que implica compartir y proporcionar buenos consejos para lograr la permanencia, y el fortalecimiento de "tradiciones" femeninas, templanza, control en todo momento de los espacios privados.

En la misma línea se antoja seguir el desempeño de su homóloga mexicana Gaby Vargas, emergida de las clínicas de diseño facial y portadora de consejos para la mujer mexicana moderna en el diario Reforma, conferencista y editora de varios libros. 
La costumbre de regalar se registra como práctica eminentemente femenina. El estudio de Isik analiza las representaciones de imágenes de maternidad en los anuncios publicados sobre el día de las madres en siete diarios urbanos de circulación nacional en Turquía. Analiza el acontecimiento a la luz de peculiares formas de celebración, regalos y comportamientos presentes en la imagen materna.

Los códigos de maternidad y de niñez como conformadores de la díada estereotípica madre-hijo se conducen ampliamente a través de esas representaciones que resultan en "posiciones maternas retóricas". La maternidad estereotipada indica la omnipresencia de las imágenes al interior de las prácticas culturales y a nivel discursivo en su conceptualización, desprovista de cuerpo sexuado. El acto de regalar y su vínculo con el género, la edad, el ciclo vital y el cuerpo implican valores esencialistas relacionados con el amor, la generosidad, "el dar y recibir" y actividad organizada y fomentada por mujeres en un día, cuya simbología reafirma el estereotipo materno articulado con otros esencialismos: el sacrificio y la abnegación, entrega incondicional y afecto al tiempo que se refuerzan relaciones de subordinación.

El día de las madres, ocasión casi obligatoria para regalar, cumple así una función de comercialización y mercantilización que se torna ejemplar en la creación de códigos vinculados con imágenes maternas.

Isik intenta interpretar dichos códigos en torno a la madre y la maternidad considerada bastión de altruismo y generosidad desinteresada.

\section{Cine y estereotipos}

Diversas imágenes de mujeres en el cine hollywoodense fueron puestas bajo la lupa de White, quien eligió los filmes más taquilleros de la década de 1980 para analizarlos.

Se pregunta si hubo cambios en la imagen femenina a raíz de los movimientos feministas del decenio de 1960 en EE.UU.

Los resultados muestran que aunque se han absorbido y procesado los retos que incluyen nuevos roles en las mujeres, prevalece la hegemonía patriarcal sobre las ideas.

Los filmes seleccionados con base en las representaciones que aparentaban retar los roles tradicionales en hombres y mujeres fueron clasificados en liberales, conservadores y reaccionarios.

El primer bloque no mostró visiones autónomas de mujer, aunque aparentemente manejaba discursos sobre igualdad; el segundo reforzaba esencialismos de género (generosidad, abnegación, desprendimiento, solidaridad, 
reina del hogar, madre eterna), mitos patriarcales con varios disfraces en donde finalmente se aniquilaba toda posibilidad de cambio. La tercera categoría incluye dos grupos de filmes: el primero llamado "tipo fierecilla domada" y el segundo "splatter films" (filmes que salpican), en donde los hombres destruyen a las mujeres por "malas" o nocivas para la sociedad.

La autora concluye que, salvo raras excepciones, los medios no son el reflejo de la sociedad, sino que proveen significados de experiencia social, modelos, lecciones morales, definen límites y aspiraciones y mantienen un orden social.

Socialización de género e imagen corporal en los medios

Halloran entrevistó a diez hombres maduros entre 35 y 39 años de edad para conocer las experiencias clave en la socialización de género y los sentimientos y significados que los acompañaban. Por medio de la técnica adleriana para registrar memorias tempranas se hicieron entrevistas en profundidad en donde se dejaba hablar al entrevistado de sus memorias para explorar las claves de la socialización del género: los canales de socialización más importantes que se registraron fueron los medios, en especial la televisión y el cine, en lo que se refiere a estereotipos de "masculinidad", "femineidad", conductas "extrañas", imagen de los padres "buenos" y "malos", cuerpo bello (1995).

\section{Revistas y estereotipos}

Kitch examina portadas de revistas femeninas a lo largo de tres décadas para registrar las diferentes representaciones de la mujer en Vogue, Elle, Marie Claire.

Refiere contextos históricos de la época y aplica la teoría de la retórica visual para señalar estereotipos de femineidad, símbolos ideológicos basados en "poder de compra" y estilos de vida. Las llama mujer "adecuada", la "típica americana (all American)", "la peligrosa", "la sofisticada y fría", "la madonna moderna".

En las últimas décadas los medios combinaban símbolos de las mujer nueva, "libre", combinada con "prestigio social" y afecta al consumismo.

Reflexiona sobre la función que desempeñó la televisión en la mercantilización de la noción de "mujer liberada", que trae como consecuencia un abandono de las ideas políticas para corresponden a la utopía de clase media.

La autora traza líneas paralelas entre la historia de la mujer y la de los medios de manera cíclica, no lineal ni procesual, y las implicaciones van en el sentido de la existencia de "climas" culturales que retornan. 


\section{Consideraciones finales}

El género como categoría de análisis y perspectiva para estudiar la imagen corporal permitió mostrar algunos de los problemas que trae consigo la creciente homogeneización de mensajes en los medios. En su calidad de industrias de la cultura de masas reducen las opciones de belleza a un número reducido de posibilidades y mensajes que las acompañan. Aunque la publicidad y la mercadotecnia arremeten cada vez más en contra de la pluralidad y heterogeneidad del cuerpo y la imagen varonil, es la mujer todavía el blanco por excelencia de mensajes mediáticos que a su vez encuentran retroalimentación en espacios y territorios en donde el culto a la imagen femenina se encuentra exacerbado.

Para probar lo anterior baste sólo hacer un breve cálculo de metros que los centros comerciales dedican a espacios femeninos, baste contar el número de programas televisivos con audiencias predominantemente femeninas, recorrer los puestos de periódico y realizar un conteo de revistas femeninas, baste consultar la sección amarilla del directorio telefónico y contar salones de belleza, estéticas que pululan a lo largo y ancho del país, abrir un diario capitalino y contar el número de cursos de belleza y personalidad que se ofrecen a las mujeres de todas edades, contar el número de libros en tiendas de autoservicio, contar la cantidad de narices femeninas que por 100 dólares moldean los cirujanos plásticos de Perú, México, Brasil, Venezuela, en clínicas ambulatorias de bajo perfil.

La revista Time dedica su portada al tema: "La locura por la cirugía plástica: mujeres latinoamericanas remodelan sus cuerpos como nunca antes. ¿Se trata de un imperialismo cultural?" (9 de julio, 2001).

Como se vio en la muestra de investigaciones que se presentaron más arriba, predominan propuestas teóricas extraídas del marxismo y del estructuralismo para el análisis sobre la imagen corporal. El cuerpo es mercancía y fetiche, y su imagen es objeto fijo de consumo, es superficie en la cual la cultura grava, vigila y castiga. El poder se detecta en las instituciones mediáticas y empresas publicitarias y de modelaje, se proyecta en la ausencia de legislación que prevalecen en nuestros medios y que soslaya su obligación de reglamentar los desmanes que se dan, sobre todo en la televisión y en las empresas publicitarias, sin ningún control. También se reconoce en la familia, la escuela, entre los amigos y grupos de presión, espacios y microfísicas cuyos movimientos estratégicos parecen reforzar el dualismo cuerpo-mente de Platón, que identifica a las mujeres con el cuerpo, caracterizado como instintivo, intuitivo, alienado, pasivo, mientras que los varones siguen siendo representados con la mente, la acción. 
Las ideologías que promueve el individualismo, cuya condición de existir ha sido el olvido de los asuntos políticos y sociales que aquejan al mundo, parecen dominar la vida cotidiana de aquellos que escogen contemplarse, emulando a Narciso.

En ese sentido proliferan modificaciones corporales, como dice Groz, que oscilan desde el maquillaje, el peinado, la disciplina aeróbica y gimnástica y las dietas hasta la cirugía plástica estética en busca de la concesión de un deseo: ser bella, ser aceptada socialmente.

También prevalecen los estereotipos en torno al cuerpo y su imagen en estrictos cortes generacionales y de ciclo vital que evocan esencialismos: las madres y amas de casa son etéreas, no tienen cuerpo, las mujeres jóvenes sí, mientras cumplan con la imagen corporal unívoca, como lo constatan los estudios de Clic, Isik, Aichison y Jordan, Firth y Gleeson.

Aunque también es cierto, como dicen Klesse y Maffesoli, que los rituales de reconocimiento identitario siempre han existido en torno al cuerpo. La insistencia mediática y publicitaria sobre construcciones reduccionistas de lo bello, vinculadas con el éxito y la perfección, ha sido costosa en por lo menos dos terrenos: en la lucha por la equidad y los derechos humanos, por ser excluyente y discriminatoria, y en el terreno de la salud mental, ya que los sondeos informan que hay muchas mujeres insatisfechas, con baja autoestima y con trastornos en la alimentación que llega a niveles epidémicos en Europa y EE.UU.

Aunque la investigación sobre dichos trastornos es incipiente en el caso de México y los datos son escasos, Unikel señala que hay pocas instituciones públicas que se dedican a atender dichos trastornos y que al Instituto Mexicano de Psiquiatría llegan mujeres a atenderse desde diferentes lugares de la República y de diversas clases sociales. Ella reporta que la presión social para estar delgado contribuye a altos índices de insatisfacción corporal y seguimiento de dietas en adolescentes y niños, con predominio de mujeres (1999: 33).

Los monitoreos cuantitativos y las herramientas etnográficas que aquí se presentaron, probaron una vez más su versatilidad -entrevistas, observación, observación participante, grupos focales-, ya que muestran que tienen el valor de acercarnos a los símbolos de la cultura como si los estuviéramos viendo por primera vez.

Este recorrido por algunos estudios sobre imagen corporal nos revela la necesidad de volver a monitorear los medios que siguen sorprendiendo al mundo académico por su capacidad de atraer a millones de mujeres y hombres con sus mensajes de belleza vinculados con éxito.

También se observa cada vez más un mayor alejamiento de los científicos sociales frente a la reflexión en torno a los contenidos que proponen: ¿acaso hubo iniciativas académicas para promover foros de opinịón sobre el fenómeno Big Brother en la televisión mexicana y las reflexiones sobre el género que 
ofrece? ¿Se ha reflexionado sobre el payaso Brozo, convertido en informador, y su acompañante femenina-cuerpo silente? ¿Se ha reflexionado sobre el asunto Gloria Trevi y su probable linchamiento mediático? iSe ha dado seguimiento a la papparazzización del periodismo mexicano y las calumnias manejadas no sólo en los programas informativos, sino en los programas de chismes como Ventaneando y La Oreja, cuyas construcciones de género giran en torno a la imagen corporal? iSe han organizado foros de reflexión sobre anuncios que promueven conductas anoréxicas, promocionan cremas para blanquear la piel, productos dietéticos riesgosos, consumo de alcohol y cigarros que en otros países están vetados?

Estos ejemplos, por citar sólo unos cuantos, muestran que en general nuestra presencia como estudiosos de los medios, salvo honrosas excepciones, está restringida y tiene poca incidencia en las políticas y en la programación mediática que día con día inventa nuevos recovecos para comercializar productos y símbolos nocivos, antidemocráticos y excluyentes.

Pareciera ser que entre más carreras de comunicación existen en el país, menos vinculación existe entre académicos y medios.

Es cierto, el vínculo es difícil. Siempre lo ha sido, pero si no aterrizamos nuestros análisis en propuestas habrá cada vez más frustración en nuestro gremio.

Algunos países han buscado afianzar el vínculo y a continuación se muestran algunos ejemplos:

La Cumbre sobre Imagen Corporal se organizó en junio de 2000 en Gran Bretaña.

A ella fueron convocados académicos, médicos, psiquiatras, psicólogos, comunicólogos, empresarios, feministas, representantes de los medios, los ministros de Salud y Educación, publicistas, agencias de modelaje y artistas.

Se lograron dos resultados concretos:

1. Promover un código de regulación para evitar la contratación de modelos extremadamente delgadas y agencias de modelos en lista negra.

2. Instrumentar un plan de acción para que la Comisión de Normatividad de los Medios Masivos de Comunicación inicie un monitoreo de tallas de mujeres que aparecen en televisión, con el objeto de evaluar si se representa la diversidad femenina (McPhail, 2002: 34).

La BBC de Londres invitó a colaborar a un grupo de investigadores de diversas universidades y a los representantes de la Asociación Británica sobre Trastornos Alimentarios en la elaboración de telenovelas que abordaban el tema y que ofrecían al final de su edición líneas telefónicas con asesoría y consultoría en el tema de trastornos alimentarios. Fue tal la respuesta del público que tuvieron que mantener un hot line durante todo el fin de semana para satisfacer la demanda. 
En EE.UU. se inició el proyecto Perro Guardián, conformado por comunicadores y ciudadanos interesados en estimular el análisis y vigilancia de medios, y del cual uno de sus logros fue lograr que la empresa Warner cancelara sus espectaculares, que anunciaban la popular serie Friends: No te pierdas a las "bellas chicas anoréxicas".

En 1999 el Instituto Canadiense de Investigación para el Desarrollo de las Mujeres (Criaw) en Ottawa, en colaboración con la revista Chateline, lanzó una convocatoria con la finalidad de explorar la relación de mujeres adolescentes con su cuerpo. Bajo el título "Es tu cuerpo, escribe sobre él" se les pidió que enviaran sus ensayos a concurso con la promesa de que premiarían a los mejores y que se abriría un taller para reflexionar sobre ellos. En total se recibieron 600 y se publicaron los mejores, acompañados de objetos artísticos y una vasta bibliografía.

La enorme riqueza de los ensayos posibilitó un análisis conjunto sobre las imágenes mediáticas y su influencia en mujeres adolescentes. Mostró que el peso, la talla corporal y su forma son preocupaciones importantes entre muchas adolescentes canadienses a la par que la educación, la salud, la carrera y la elección de pareja. Incluso muchas de ellas confesaron sentir odio por ellas mismas por no alinearse a los patrones de belleza que la sociedad dictaba.

Durante el taller quedó claro que el cuerpo es una construcción cultural y que mientras cada cuerpo es original y único, los cuerpos también son conformados y marcados por culturas e historias específicas.

El dolor en estas historias se relaciona con normas sobre femineidad definidas a través de la forma del cuerpo ideal. La obligación-obsesión de ser delgada y la opresión sobre la gordura son rasgos fundamentales de los patrones actuales de femineidad en la sociedad occidental. Muchas de las historias describen la relación tortuosa de las mujeres con la comida y su intento de hacer dieta hasta la inanición.

Desde una perspectiva feminista, todas estas prácticas se relacionan con la producción social de la femineidad y la opresión de las mujeres, reflejada en los medios y en la cultura popular en general.

Sin embargo, no sólo son historias de dolor, tensión y decepciones, sino también documentan la alegría, la autoestima a través del amor y el cuidado del cuerpo como fuente de sensualidad, logros atléticos o deportivos, espiritualidad y como expresión artística y vehículo para el arte y la creatividad.

En 2001 se realizaron programas de "alfabetización literaria" en la Universidad de Cambridge con apoyos mediáticos, como videos que entrenan a los usuarios en la visión crítica de los medios para reducir las imágenes corporales negativas en una muestra de mujeres universitarias. Se realizaron talleres piloto en escuelas públicas de la región. 
A raíz de un sondeo que realizó la revista Psychology Today en 2001 mostró que $56 \%$ de todas las mujeres están insatisfechas con sus cuerpos, se instrumentó un curso sobre estrategias para subir la autoestima y elevar la confianza y "amar" su cuerpo.

Los consejos de los expertos de la escuela de Medicina de Harvard señalaban:

1. No voy a criticar mi cuerpo. Yo soy mi peor crítico. Muchas madres que lo hacen tienen madres que lo hacían con ellas. Están más cómodas con críticas que con halagos.

Hay que vetar los pensamientos negativos sobre el cuerpo, ya que pueden tener consecuencias negativas sobre otras áreas y afectar la autoestima.

2. No voy a tenerle miedo al espejo. Debes observarte en el espejo para reducir tu ansiedad.

Estar a gusto con tu cuerpo, con la meta de aceptar tus imperfecciones.

3. No voy a compararme con la perfección. Recuerda que la mujer estadounidense promedio mide 5 pies 4 pulgadas y pesa 140 libras, mientras que las modelos pesan 117. Esto las hace más delgadas que $98 \%$ de la población de EE.UU.

Siempre habrá mujeres con mejores cuerpos que el tuyo, así que es un círculo destructivo el hecho de pesarte y compararte con ella. En lugar de eso, compárate contigo misma y recuerda que no necesitas ser perfecta.

La comunicóloga y académica Diane Samples condujo por primera vez y como proyecto piloto el programa Club Media con 28 niños entre 10 y 12 años en Colchester, Vermont.

Con el objetivo de que los niños desarrollen una visión crítica frente a los medios se organizó este curso y se reflexionó sobre las siguientes preguntas. ¿Quién crea los mensajes y por qué? ¿Qué información se omite que puede ser importante? ¿Puedes creer lo que ves? ¿Cómo se hace el mensaje?

Cada día los instructores trabajaron sobre temas que abarcaban fraseos tramposos en anuncios. Por ejemplo: "el cereal es parte de un desayuno balanceado" y no, como dice el comercial "es un desayuno balanceado". También se vieron ejemplos de manipulación digital de imágenes corporales en publicidad.

A raíz de esta experiencia Samples fundó Media Knowledge (Conocimiento sobre Medios), una organización no lucrativa que conduce talleres para niños, padres y educadores y señala la ausencia de estos programas en la educación primaria en EE.UU. Afirma que los programas de educación sobre medios deben ser incluidos en el currículo escolar con personal entrenado que los conduzcan.

En un taller llamado "Media Awareness" (Conciencia sobre los Medios) y con la finalidad de registrar las maneras en que se construye el ideal de delgadez en la televisión, se ofreció un taller para mujeres amas de casa en 
Vancouver, Canadá, que buscaba analizar el contenido de programas cómicos en cuanto a la imagen corporal femenina y los reforzamientos verbales que recibían ellas al respecto. Se monitorearon 28 programas con alto nivel de audiencia y se registraron los comentarios verbales acerca del peso y la talla de las principales protagonistas. Hubo discursos de aprobación sobre conductas dietéticas y pérdida de peso, así como discursos de burla o estigmatización de mujeres gordas. Se discutieron los resultados en el taller.

Con este colofón, el presente artículo propone la necesidad de vincular el mundo académico con los medios, que los reconozca, elabore proyectos conjuntos, realice monitoreos con pares y alumnos, trabaje con ellos en el reconocimiento de áreas problema y en la elaboración de contenidos que diviertan sin enajenar a la población. Es tarea difícil pero necesaria para mostrar a las generaciones de alumnos que se están formando que sí es posible trabajar conjuntamente.

\section{Bibliografía}

Aichison, C. y F. Jordan (2001), Beauty and the Beach: Discourses of Tourism and the Body. Women Studies Network Seminar, Gran Bretaña.

Becker, A. (1998), The View from Fiji, EE.UU., Pennsylvania Press.

Bordo, S. (1993), Unbearable Weight, EE.UU., California Press.

Click, M. (2001), Consuming Perfection or Perfecting Consumption? Women Studies Network Seminar.

Colls, R. (2001), Body Shopping: Exploring the Spatial and Embodied Experiences of Women's Clothing Consumption, WSN.

Criaw (1999), That Body Image Thing: 600 Young Women Speak Out, Canadá, Criaw-Icref.

Curtin, M. (2001), Taming the Skin on the Techno-catwalk at the World Class Pace: Nike's Evolution in Race and Gender, wSN.

Cusamano, D. et al. (1997), "Sex Roles", en Journal of Social Issues, noviembre, pp. 701-721.

Chew, W. (2001), The Gendering of National Stereotypes in Early American Travel Accounts: the Case of France, WSN.

Cusamano, D. y J. Thompson (2000), "Media Influence and Body Image in 8-11 Year Old Boys and Girls International”, en Journal of Eating Disorders, vol. 29, núm. 1.

Dorfmann, A. y A. Mattelart (1971), Para leer al pato Donald, Chile, Ediciones Universitarias Valparaíso. 
Eskes, T. et al. (1998), "Health and Beauty Issues", en Journal of Sport and Social Issues, núm. 22, agosto, pp. 317-344.

Fallon (ed.) (1994), Feminist Perspectives on Eating Disorders, EE.UU., The Guilford Press.

Fass, A. (2000), "Club Media, a Camp to Teach your Children the Secrets of Marketing”, en New York Times, 31 de agosto.

Foucault, M. (1976), Vigilar y castigar, México, Siglo XXI.

Foucault, M. (1978) Microfísica del poder, Madrid, La Piqueta.

Friedan, B. (1963), The Feminine Mystique, EE.UU., Dell.

Frith y Gleeson (2001), Too Much Too Young: Signalling Mature Sexual Identities Through Clothing Consumption, WSN.

Groz, P. (2000), "Body Modifiers”, en Sociology, vol. 1, núm. 23.

Heywood, L. (1998), Bodymakers: a Cultural Anatomy of Women's Bodybuilding, EE.UU., Rutgers U. Press.

Hodgson, J. (2001), "Britain Covets Celebrity Bodies", en The Guardian, 19 de abril.

Isik, F. (2001), Selling on Mother's Day: on the Representations of Mother (hood) Image (s) in Mother's Day Ads, wSN.

Kennedy, A. (2001), Living on the Outside-interpellation of Women by Dress and the Discursive Position of "Abnormal", WSN.

Lamas, M. (2002), Cuerpo: diferencia sexual y género, México, Taurus.

Lipovetsky, G. (1987), La era del vacio, México, Anagrama.

Liuccio, M. (1998), "Food and History in Postmodernism", en Sociologia, núm. 32, pp. 265-271.

Maffesoli, M. (1996), The Time of the Tribes, Londres, Sage.

Maguire, J. y J. Mansfield (1998), “No-body's Perfect”, en Sociology of Sport Journal, núm. 15, junio, pp. 109-137.

Markula, P (1995), "Firm but Shapely, Fit But Sexy, Strong But Thin: the Postmodern Female Bodies", en Sociology of Sport Journal, núm. 12, diciembre, pp. 424-453.

Mc Luhan. M. (1964), Understanding Media, EE.UU., Signet.

Mc Kabe, M. (2001), "Parent, Peer and Media Influences", en Adolescence, vol. 36 , núm. 142 , verano.

McPhail, E. (2002), “La imagen corporal”, en Etcétera, México, agosto, pp. 33-37.

Media Awareness Workshop (2001), en: www. mediaworkshops. canada.

Nasser, M. (1997), Culture and Weight Consciousness, Gran Bretaña, Routledge. 
Tolman, D. y E. Debold (1994), "Conflicts of Body and Image: Female Adolescence, Desire and the No-body body", en Fallon (ed.) (1994), Feminist Perspectives on Eating Disorders, EE.UU., Guilford Press.

Samples, Diane (2001), Media Knowledge Workshop, EE.UU.

Tracy, I. et al. (2001), "Examination of Model of Sociocultural Influences", en Adolescence, vol. 36, núm. 142, verano.

Ullen, M. (2001), This is Hardcore: Gender, Advertising and the Pornographic Structure of Consumerism, wSN.

Watson, S. (2001), "Navel Gazing", en The Guardian, 30 de junio.

Watch Dog Program, en: www.edap.org/watchdog.

Wolf, N. (1991), The Beauty Myth, EE.UU., Anchor Books. 